\title{
P01-049 - Assessment of vascular function in systemic JIA
}

\author{
B Sozeri ${ }^{*}$, K Ozdemir $^{1}$, S Mir ${ }^{1}$ \\ From 7th Congress of International Society of Systemic Auto-Inflammatory Diseases (ISSAID) \\ Lausanne, Switerland. 22-26 May 2013
}

\section{Introduction}

An increased incidence of cardiovascular disease has been found in rheumatic disorders. Juvenile idiopathic arthritis (JIA) is the most common chronic rheumatic disease in children. Prolonged immunological inflammatory process leads in these patients to an early onset of atherosclerosis.

\section{Objectives}

We aimed to assess the presence of early vascular dysfunction in patients with systemic onset juvenile idiopathic arthritis (SoJIA) and investigate the role of therapy SoJIA in vascular health.

\section{Methods}

Eighteen patients ( 12 males, 6 females) with diagnosis of SoJIA according to the International League of Associations for Rheumatology criteria were compared to 75 ageand sex-matched controls. No participant was overweight, obese, or had a history of hypertension, dyslipidemia, diabetes mellitus, or cardiovascular disease. Arterial stiffness (As) was evaluated by measurement of carotid-femoral pulse wave velocity (PWV) and augmentation index (AIx) with Vicorder.

\section{Results}

The mean age onset of disease was $80,4 \pm 28,7$ months (range 36-122months). The mean duration of disease and active disease was $79 \pm 45$ months (range 6-162 months) and $58 \pm 49$ months (range 1-161 months), respectively.

Patients with SoJIA presented a higher mean PWV and AIx than in controls $[(6.16 \pm 1.45 \mathrm{~m} / \mathrm{s}$ vs $5.19 \pm 0.63 \mathrm{~m} / \mathrm{s}$, $\mathrm{P}=0.01)$ and $(14.7 \pm 8.1 \% \mathrm{vs} 10.4 \pm 7.35 \%, \mathrm{P}=0.02)]$. Eight (44\%) patients with JIA had active disease at study entry. The highest levels of PWV and Aix were found in active patients. Six patients had been macrophage activation syndrome at presentation. In these patients, vascular changes higher than other patients $(6.30 \pm 0.42 \mathrm{~m} / \mathrm{s}$ vs 5.17 $\pm 0.55 \mathrm{~m} / \mathrm{s}, \mathrm{P}=0.01$, respectively). The corticosteroid therapy was found associated with higher PWV, $(\mathrm{P}<0.05)$, while there was not different between vascular parameters and used non steroid therapy (NSAIDs, MTX, or antiTNF agents). We also find statistically significant correlation between PWV and disease duration $(\mathrm{p}=0.003$, $\mathrm{r}=0.45$ ).

\section{Conclusion}

Vascular function is impaired in patients with SoJIA at a very young age. Vascular dysfunction may be partly attributed to the effects of disease-related characteristics (inflammation, disease activity, and medications).

\section{Disclosure of interest}

None declared.

Authors' details

${ }^{1}$ peadiatric nephrology, Ege University, Izmir, Turkey. ${ }^{2}$ pediatric rheumatology, Ege University, Izmir, Turkey.

Published: 8 November 2013

doi:10.1186/1546-0096-11-S1-A52

Cite this article as: Sozeri et al:: P01-049 - Assessment of vascular function in systemic JIA. Pediatric Rheumatology 2013 11(Suppl 1):A52.

2 pediatric rheumatology, Ege University, Izmir, Turkey

Full list of author information is available at the end of the article

(c) 2013 Sozeri et al; licensee BioMed Central Ltd. This is an Open Access article distributed under the terms of the Creative Commons 